\title{
Fingerprinting Soil Water Evaporation with Triple Oxygen Isotopes of Pedogenic Carbonates
}

Julia R. KELSON, TYleR E. Huth, NAOMI E. LEVIN, BENJAMIN H. PASSEY ${ }^{1}$

${ }^{1}$ University of Michigan, Earth and Environmental Sciences, 1100 North University Avenue, Ann Arbor, MI, 48109, jrkelson@umich.edu

The oxygen isotope composition of soil carbonates $\left(\delta^{18} \mathrm{O}\right)$ is widely used to investigate terrestrial paleoclimates. The underlying assumption is that the $\delta^{18} \mathrm{O}$ value of soil carbonates reflects the $\delta^{18} \mathrm{O}$ value of meteoric waters. This assumption is violated if soil carbonates form in soil waters that have been evaporatively enriched in heavy isotopes. In theory, the triple oxygen isotope composition $\left({ }^{16} \mathrm{O}-{ }^{17} \mathrm{O}-{ }^{18} \mathrm{O}\right)$ of pedogenic carbonates can be used to identify evaporation in soil water: kinetic evaporation will cause the relationship between $\delta^{17} \mathrm{O}$ and $\delta^{18} \mathrm{O}$ to deviate from that defined by the global meteoric water line. Here, we present $\Delta^{17} \mathrm{O}$ values of recent soil carbonates from a range of climatic settings, with the goal of identifying the relationship between local aridity and the extent of evaporation in the soil waters from which carbonates accumulate. Preliminary $\Delta^{17} \mathrm{O}$ values of soil carbonates (as $\mathrm{CO}_{2}$ from $90{ }^{\circ} \mathrm{C}$ acid digestion) range from -0.100 to $-0.180 \%$. The highest $\Delta^{17} \mathrm{O}$ values are consistent with soil waters with minimal evaporative-enrichment of heavy isotopes, perhaps resulting from soil carbonate precipitation related to non-evaporative processes (e.g., dewatering by plant-root uptake or changes in temperature or soil $\mathrm{pCO}_{2}$ ). The lowest $\Delta^{17} \mathrm{O}$ values indicate extensive evaporation of soil waters and are only observed in arid climates. These results suggest that $\Delta^{17} \mathrm{O}$ in soil carbonates will be useful in identifying and correcting for evaporative modification of $\delta^{18} \mathrm{O}$ values. In the modern environment, $\Delta^{17} \mathrm{O}$ promises to further our understanding of the timing and mechanisms of soil carbonate formation. 